\title{
The Extent of Practitioners' Involvement in the Delivery of Sustainable Urban Regeneration Projects in UK
}

\author{
By Julius Akotia ${ }^{1}$, Alex Opoku ${ }^{2}$ and Farahat $\mathrm{Hafiz}^{3}$
}

\begin{abstract}
The requirement to deliver successful sustainable regeneration projects places enormous responsibility on the construction industry practitioners. While the concept of sustainable regeneration has being a big issue in the UK, and also being in operation within the construction industry over the years, it can be said that its achievement has been hampered and determined by numerous factors. One such factor which has affected and continues to affect and determine the sustainability outcome of regeneration projects, are the key practitioners who are tasked with the responsibility of delivering such regeneration projects. The findings of a study that obtained 193 responses through a questionnaire survey to explore the key practitioners' levels of involvement in the delivery of sustainable regeneration projects in the UK is presented in this paper. The findings identified varied levels of practitioners' involvement in the three main stages of the project delivery/development; early, construction and post construction. The findings revealed that clients' representatives, commercial managers and architects were the most frequently involved practitioners during the early stages of the projects. The findings also indicated that practitioners who have sustainability assigned to their roles and their responsibilities, such as the regeneration managers, sustainability managers, training/corporate social responsibility managers were the least frequently involved in all the three delivery stages of the projects.
\end{abstract}

Keywords: Sustainable regeneration, Key Practitioners, Level of involvement, Urban regeneration

\section{Introduction}

The involvement of key practitioners is aimed at capturing their knowledge and contributions into the project development and the delivery processes (Mathur et al., 2008). In the context of regeneration, the involvement of the key players in a project is fundamental to the delivery of the project outcomes. It is important to establish the roles and the levels of involvement of the key actors as this is crucial to the promotion, implementation and attainment of sustainability of the sustainable regeneration projects. Conventionally, the interactions and linkages between the key players ultimately influence and determine the overall performance of the projects (Takim, 2009). Adopting and implementing sustainability on regeneration projects can be influenced by key practitioners involved in the delivery of the project. It has also been argued that, engaging appropriately key participants in a project delivery processes can help to deliver a wide range of project outcomes (Mathur, et al., (2008). The aim of this paper is to explore the key practitioner's levels of involvement in the delivery of sustainable

${ }^{1 \& 3}$ University of East London, School of Architecture, Computing \& Engineering, London, E16 2RD.

${ }^{2}$ UCL Bartlett School of Construction \& Project Management, University College London, London, WC1E 7HB. 
regeneration projects in the UK. To achieve this, the papers begins by providing the background literature on the impacts and importance of the key practitioners' involvement in the sustainable regeneration projects delivery process, ... and goes on to present the findings and analyses from quantitative data obtained from 193 practitioners through survey.

\section{The concept of Sustainable Development}

Sustainable development has emerged as a new paradigm and a guiding principle for development activities around the world (Jaillon and Poon, 2008). The World Commission on Environment and Development (WCED), also known as the Brundtland Commission (1987) "Our Common Future", defined sustainable development as: "development that meets the needs of the present generations without compromising the ability of future generations to meet their own needs" (WCED, 1987:43). The Brundtland Commission definition formed the basis and guiding principle for socio-economic and environmental issues and policies which sought to take a proactive action and decision to address the current deterioration situation and deal more efficiently with development problems for the future generations. It presented a significant milestone and set out a new development agenda and framework for socio-economic sustainability of humanity (Edum-Fotwe and Price, 2009). The Commission laid the foundation for subsequent United Nations deliberations such as Rio Declaration (UNCED, 1992), which took the concept of sustainable development further by formulating the Agenda 21 which sought to harmonise not only the socio-economic and environmental sustainability deliverables, but also set out mechanisms for expressing our collective responsibility towards the future generations (Thomson, et al., 2009). The decision to adopt sustainable development concept including those contained in the United Nations Millennium Declaration, gave overall political direction and form the basis for the implementation of sustainable development objectives by many agencies.

In the UK for instance, the government has been championing the adoption of sustainable development goals by engaging construction organisations to adopt more sustainable construction practices and processes in the delivery of their projects (Carter and Fortune, 2007). Its sustainable development strategy has been focused on addressing the underlying social and economic challenges by providing support for people particularly in the most deprived communities, to access new opportunities in a number of areas (CLG, 2008). Van Bueren and De Jong (2007); Cater and Fortune; Matar et al. (2008) and other authors such as Opoku and Ahmed, (2014) emphasised that the introduction of sustainability concept has brought about new measures and challenges to the industry practitioners and policy makers. They identified sustainable development as an opportunity by which construction projects can also be used to contribute its' quota to the larger effort towards the achievement of universally shared human socioeconomic well-being and prosperity.

Accordingly, the quest to deliver such sustainability benefits has been the drive behind the introduction of numerous initiatives and policies, particularly in the UK. One of such initiatives has been the promotion of sustainability benefits, in particular, the socioeconomic ones through the delivery of construction projects, such as regeneration 
projects. The promotion of such sustainable regeneration policy has played a major role in directing many regeneration activities, both at the national and local levels in the UK to deliver sustainability benefits for communities to tackle the developmental needs of the present and future generation (SDC, 2003). It has widely been acknowledged that improving the regeneration projects' sustainability performance can propel efforts towards the greater achievement of sustainable development benefits in the long term (Mang and Reed, 2012). According to HM Treasury, (2007), achieving sustainable development goals form a crucial aspect of realising a significant socio-economic regeneration and transformation of the present and future generations.

\section{Sustainable Regeneration}

The objective of the sustainable regeneration concept according to CLG, (2009); SDC, (2003), is to transform society by creating sustainable places where people want to live, work and feel secure. It also means meeting the sustainable development needs of the people in a way which delivers social progress, economic growth, environment protection, and a better quality of life (SDC, 2003). In more recent times, there has been a number of research works which sought to study and analyse how the UK built environment was responding to the challenges of integrating sustainability into regeneration projects (Dixon, 2006). The Sustainable Development Commission (SDC, 2003) for example suggested that, the development and delivery of regeneration projects has proved to be a testing and on-going challenge for government agencies, construction industry practitioners and communities in which regeneration projects have been sited. In their seminal work, Jones et al., (2003) argued that achieving successful sustainable regeneration has proved to be elusive and difficult to deliver due to lack of understanding and over generalisation of sustainability factors. Winston (2009) for instance, identified many such problems associated with the successful delivery of sustainable regeneration initiatives to be of a social and economic nature rather than the environmental aspects of the projects. The Audit Commission Report (2007) has revealed that many sustainable regeneration projects are yet to have a consistent and positive impact on the most deprived localities in which the projects have been implemented. For example, the report indicated that the level of long-term unemployment in such 'so called regenerated' communities has remained static and targeted work to develop skills and access to sustainable jobs and employment for these communities has remained under-developed.

According to Brandon and Lombardi (2011), previous works undertaken on sustainable regeneration have shown that they lack a conceptual clarity related to the evaluation of sustainability outcomes of the projects. They argued that most of the existing evaluation methods designed for regeneration projects were based on environmental indicators that were derived from ideas and assumptions of individual practitioners. Numerous attempts aimed at delivering sustainable regeneration have primarily been limited to the environmental performance of the projects (Reyes et al., 2014). Although a number of evaluation systems have been developed over the period, their focus and considerations have largely remained limited to evaluating the environmental impacts of the projects. Many of the earlier regeneration initiatives that were meant to address socio-economic 
disparities have focused on improving the environmental aspects of regeneration. This has resulted in many sustainable regeneration projects' inability to deliver their intended sustainability objectives.

However, it has been suggested that improving the socio-economic sustainability aspects of regeneration projects can potentially enable sustainable regeneration projects to deliver better sustainability outcomes to address the socio-economic disparities that were entrenched in the communities (Haran et al., 2011; Adamson, 2010; CLG, 2008). In this regard, Smith (2006) argued that sustainable regeneration projects should not only focus on addressing environmental aspects, but should also consider the broader issues of social and economic sustainability factors of the projects as well. Similarly, it is also suggested that sustainable regeneration projects can reinforce a sense of community confidence, makes an important contribution to the local economy and also act as a catalyst for improving the wider area (Office of Deputy Prime Minister (ODPM), 2005), if the social and economic sustainability deliverables are well incorporated and delivered as an outcome of the projects. However, this will require innovative practices and evaluation systems that are capable of embracing other dimensions beyond the current consideration of sustainability, and not the one that just focuses only on environmental dimension (Dixon, 2006; SDC, 2003). In this regard the built environment practitioners also have a key role to play in ensuring that sustainable regeneration projects deliver the required socio-economic sustainability benefits.

\subsection{Key practitioners' involvement in Sustainable Regeneration projects}

In the context of sustainable regeneration, the involvement of key players in the delivery of projects is fundamental to the projects' sustainability outcomes. It is important to establish the roles and the level of involvement of practitioners, as these are crucial towards the adoption and implementation of sustainability features in regeneration projects. Conventionally, the interactions and linkages between these key players ultimately influence and determine the overall performance of the projects (Takim, 2009). It has also been argued that engaging key practitioners appropriately in the project delivery processes can help to influence efforts towards the adoption and implementation of a wide range of sustainability deliverables for the projects (Mathur, et al., 2008).

Numerous challenges associated with the management of projects' teams identified by previous contributors include inadequate involvement and undefined roles of key stakeholders among others factors (Yang et al., 2009). Sustainable construction projects, and in particular, regeneration projects consist of a number of complex and interactive activities which require a number of practitioners to deliver them. It has been said that sustainability features in regeneration projects are multifaceted and often subjected to different processes and interpretations during different stages of the project, and therefore require a collective approach to drive the sustainability processes of the projects. Feige, et al. (2011) pointed out that the sustainability concept in itself causes various forms of challenges to different groups of practitioners and stakeholders. According to Mathur et al. (2008), the contesting nature of sustainability issues and the benefits associated with the delivery of sustainability projects, provide a compelling case to effectively engage key players in their delivery processes. The processes and activities 
involved in delivering sustainable regeneration projects are also often considered as complicated. Such complexities have also been cited as one of the reasons for many practitioners' inability to adopt and implement sustainability features on their projects in practical terms (Tippett et al., 2007).

The complexity and the multifaceted nature of sustainable regeneration projects, coupled with the implications and impacts of sustainability, make it even more crucial to engage key players in the delivery of sustainable regeneration projects. Hence, the requirement to adopt and implement sustainability features in regeneration projects, taking into account the multi-dimensional issues and impacts, calls for a "multi-scale, trans-disciplinary and pluralistic approach that is able to integrate and synthesise the many different perspectives" for the project (Lombardi, 2009: 179). In that way, many sustainability challenges associated with the execution of such complex activities and processes can well be dealt with. It is only then that such a project's sustainability deliverables can be addressed collectively. The performance and achievement of the projects' sustainability outcomes largely depends on the inputs from these players. It is believed that sustainability features would be best executed when key players are actively represented in such regeneration delivery processes. Adequate involvement of key players will also ensure effective collaboration to overcome any possible difficulties and divisions, which are likely to undermine the projects' success. Active and effective involvement, particularly at the conception stages of the projects is considered as fundamental towards the adoption and implementation of sustainability factors in regeneration projects.

It is suggested that focusing attention on the selection and formation of the main project team early in the planning stages is fundamental in achieving the successful delivery of a project's objectives (DBIS, 2013; Rowlinson et al., 2008). It is believed that a project team, if well- formulated, with individual practitioners well represented in the team formation process, would enable such practitioners to understand what is required to be achieved in terms of sustainability (Mathur et al., 2008). Apparently, such an approach will also help to foster a strong spirit of corporation among practitioners, overcome divisions and oppositions to new ideas, build consensus to create "a contextspecific interpretation of sustainability" and align the project's sustainable objectives with practitioners' perspectives (Mathur et al., 2008: 606).

\subsection{The role of key Practitioners' in the delivery of Sustainable Regeneration projects}

In the context of this study, the role of practitioners refer to their professional background (i.e. architect etc.), while the responsibilities refer to the core duties (i.e. preparing drawings, designing etc.) they perform in the delivery of the projects. Also, for the purpose of this study, the practitioners identified to be mainly involved in the delivery of regeneration projects, who participated in the study, are referred to as key practitioners. Below are the identified key practitioners, their roles and responsibilities in the delivery of sustainable regeneration projects:

- Architect: is the practitioner tasked with the responsibility of producing the drawings and design solutions of the project to meet the client's needs/requirements. 
- The client's representative: for the purpose of this study, the client representative is any practitioner representing the client's interests on the project. The greatest responsibility for achieving the client's requirements lies with the client's representative, who is one of the most influential practitioners in the construction project delivery processes.

- Project manager: is the practitioner responsible for managing and coordinating processes, resources (including other practitioners on a daily basis), and facilitating effective delivery of all the projects' deliverables, to meet all the requirements of the projects, and also provides other construction information on progress and variations. A key practitioner for the adoption and implementation of decisions etc., for the project.

- Commercial manager: is the practitioner responsible for managing and controlling the cost aspects of the project.

- Sustainability manager: is the practitioner responsible for the sustainability aspects, including the social, economic and environmental aspects of the project. They are responsible for ensuring that all other practitioners, including the client's representative, are aware of their sustainability responsibilities in relation to sustainable construction projects.

- Regeneration manager: is the practitioner responsible for developing regeneration strategies for the project and ensuring that sustainable regeneration features are incorporated into the project to deliver a wide range of regeneration outcomes for stakeholders, including the local community. They provide advice on sustainable regeneration deliverables to the project team/practitioners.

- Training/corporate social responsibility (CSR) manager: is the practitioner responsible for ensuring that the local content is incorporated in the project. This includes recruitment and procurement of local labour and materials, and training and apprenticeships and work placements etc., for local people on the project.

The involvement of the above key practitioners for the purpose of this study means engaging them as participants in the discharge of their responsibilities in the delivery of regeneration projects. In this regard, the words 'involvement' and 'engagement' are used interchangeably to mean the same thing in this study.

All the key practitioners were asked questions about their level of involvement in the delivery of sustainable regeneration projects at these three main stages (early, construction and post construction) of the sustainable regeneration projects' delivery in undertaking the following activities, such as; planning and preparation (PP), adoption and implementation (AI), coordination and supervision (CS), and monitoring and evaluation (ME) in line with Royal Institute of British Architects' (RIBA) plan of work (2007) as shown in Table 1.

Table1: RIBA outline plan of work and project delivery activities

\begin{tabular}{|l|l|l|l|l|l|}
\hline $\begin{array}{l}\text { Stages/ } \\
\text { Activities }\end{array}$ & \multicolumn{2}{|l|}{ Early Stage } & \multicolumn{2}{l|}{ Construction Stage } & Post Construction Stage \\
\hline $\begin{array}{l}\text { RIBA main } \\
\text { work stages }\end{array}$ & Preparation & Design & Pre-Construction & Construction & Use \\
\hline Activities & PP & AI and CS & ME \\
\hline
\end{tabular}

At the early stage of the projects' delivery, the main activities that are performed by the key practitioners are planning and preparation. Although planning and preparation are two separate words, they are employed in this study to refer to all the activities that are required to be undertaken before the commencement of the construction stage of the 
project. These include feasibility, goal setting, design, etc. Planning and preparation could be useful to ensure a greater buy-in from all the key practitioners, to achieve a common objective for the project. Undertaking planning and preparation activities would help to set out performance targets for other activities (i.e. AI, CS, and ME).

At the construction stage of a projects' delivery, the main activities that are to be undertaken include adoption and implementation, and coordination and supervision. Adoption refers to the embracement of activities from the early stage, while implementation is concerned with implementing the adopted activities; in other words, putting the 'adopted' activities into practice. Coordination activities entail the interaction and integration of work and resources, while supervision activities on the other hand are concerned with overseeing the performance of works and resources. At the post construction stage of the projects' delivery, the activities that are required to be carried out in the context of this study include monitoring and evaluation. Even though the words 'monitoring' and 'evaluation' are two separate words, they are used in this context to mean the tracking of performance towards the specified targets set out at the early and construction stages of the projects' delivery processes.

\section{Research Methodology and Data Collection Approach}

The study adopted quantitative research approach, using questionnaire survey to collect data from the key practitioners identified to be involved in the delivery of sustainable regeneration projects within their construction organisations. Saunders et al. (2009) suggested that the adoption of a questionnaire technique allows the researcher to exercise some level of control over the data collection process, and by so doing, enables the researcher to obtain results from the study that are representative and generalisable to the entire population. Indeed, such questionnaire surveys technique have been extensively utilised to collect construction project related information for similar reasons (Fellows and Liu, 2003). In line with the advantages noted above, questionnaire survey approach was adopted as it enabled representative data to be collected speedily from the entire population. The questionnaire survey was designed and administered on online using survey 'SurveyGizmo' software. According to Bryman (2008), using online questionnaires provides many advantages. They facilitate easy and speedy responses and reach out to a large number of respondents in a cost effective manner, irrespective of distance and location. They also allow for "a much wider variety of embellishments in terms of appearance" (Bryman, 2008: 645) than can be achieved through the traditional mailed approach. In respect of this, online questionnaire survey was adopted for this study which was administered through the internet to collect data from a large population in a timely manner.

The focus of the study is on sustainable regeneration projects in the UK. Therefore, to ensure adequate representation and balance of knowledge and experience, a well-defined sampling framework was used. For this study, given that the research is based on quantitative research, a stratified random sampling approach was adopted, using sampling frames, containing a list of 300 leading construction organisations published by turnover in the 2014 editions of the Building Magazine and New Civil Engineer Magazine in the UK, who have been involved in the delivery of sustainable regeneration 
projects over the years. In all, a total of three hundred (300) hyperlinks were emailed out to the selected respondents, sampled randomly from the list described above that are involved in the delivery of sustainable regeneration projects/ programmes across the UK. The respondents email addresses were obtained through telephone calls and also a search on the organisations' websites. Pre-survey contacts were then made through telephone calls and emails before the final questionnaire survey was sent out to them. Follow-up emails were sent out and telephone calls were further made two weeks later to remind those who were yet to respond to it. This was done to further emphasise the importance of completing the questionnaire on time and also to increase the response rate (Saunders et al., 2009). Overall, within a period of 4 weeks, a total of 193 responses were received, representing a response rate of $64.33 \%$ out of the total selected sample of 300. A 5-point Likert scale ("1" representing the "highest" and "5" the "lowest") approach was adopted by the questionnaire to collect the primary data. Respondents were asked to indicate the extent to which there were/have been actively involved in the delivery (three main stages) of sustainable regeneration projects in the UK ranging from "1" (always involved) to "5" never involved. The responses obtained were then downloaded from the 'SurveyGizmo' software and exported into the Statistical Package for the Social Sciences (SPSS) for the analysis of the data. Table 2 shows the breakdown of the questionnaire distribution, completion rate, and the response rate respectively.

\section{Data Analysis}

A descriptive analysis and inferential statistic were adopted to analyse the data obtained from respondents. According to Seale (2005) the use of descriptive analysis, in particular, the determination of mean and percentage values provides a measure of central tendency and an indication of dispersion of the data. Hence, a descriptive analysis (Table 3 and 4) was then conducted to obtain the percentage (\%) distribution and mean values for the responses. Further Relative Important Index (RII) analysis was carried out using equation (1) below, to obtain the RII values to enable ranking (most involved) of the scores as shown in Table 4. Ali, et al, (2008) have also utilised the RII to analyse the level of practitioners' involvement in the design of refurbishment projects. Conducting RII analysis helped to compliment the results obtained from descriptive analysis, by providing a higher degree of confidence of the results. The Relative Important Index (RII) analysis is carried out using the formula:

$$
\mathbf{R I I}=\underset{\mathbf{A}^{*} \mathrm{~N}}{\sum_{(\mathrm{W})}}(0 \leq \mathrm{RII} \leq 1)
$$

Where $\mathrm{W}=$ weights given to each factor by the respondents and will ranges from 1 to 5 , where ' 1 ' is less significant and ' 5 ' is extremely significant. $A=$ highest weight (i.e. 5 in this case), and $\mathrm{N}=$ total number of respondents. With the results (Table 4), and as per the 5-point Likert scale ("1" - highest" and "5" - lowest), the lower the mean (M) and RII values, the higher the level of involvement in the delivery of the project. 
Table 2: Questionnaire survey distribution, completion and response rate

\begin{tabular}{|l|l|l|l|l|}
\hline $\begin{array}{l}\text { Organisation } \\
\text { Category }\end{array}$ & $\begin{array}{l}\text { Questionnaire } \\
\text { Distributed }\end{array}$ & $\begin{array}{l}\text { Completed } \\
\text { Questionnaire } \\
\text { Received }\end{array}$ & $\begin{array}{l}\text { Questionnaire Not } \\
\text { Completed }\end{array}$ & Response Rate \\
\hline $\begin{array}{l}\text { Construction } \\
\text { organisation }\end{array}$ & 300 & 193 & 107 & $64.3 \%$ \\
\hline Total (N) & $\mathbf{3 0 0}$ & $\mathbf{1 9 3}$ & $\mathbf{1 0 7}$ & $\mathbf{6 4 . 3 \%}$ \\
\hline
\end{tabular}

Table 3: Questionnaire survey descriptive results (\%) of practitioner's level of involvement in the three main stages of sustainable regeneration projects

\begin{tabular}{|c|c|c|c|c|c|c|}
\hline \multicolumn{2}{|c|}{ Stakeholders (key players) } & $\begin{array}{l}\text { Always } \\
\text { involved } \\
(\%)\end{array}$ & $\begin{array}{l}\text { Very often } \\
\text { involved } \\
(\%)\end{array}$ & $\begin{array}{l}\text { Sometimes } \\
\text { involved } \\
(\%)\end{array}$ & $\begin{array}{l}\text { Rarely } \\
\text { involved } \\
(\%)\end{array}$ & $\begin{array}{l}\text { Never } \\
\text { involved } \\
(\%)\end{array}$ \\
\hline \multirow{7}{*}{ Early Stage } & Architect & 43.0 & 39.4 & 10.9 & 5.2 & 1.6 \\
\hline & Client representative & 58.5 & 30.6 & 6.7 & 3.1 & 1.0 \\
\hline & Project manager & 17.1 & 48.7 & 23.3 & 9.3 & 1.6 \\
\hline & Commercial manager & 53.4 & 33.2 & 8.8 & 2.6 & 2.1 \\
\hline & Sustainability manager & 15.5 & 45.6 & 25.9 & 8.3 & 4.7 \\
\hline & Regeneration manager & 11.4 & 24.4 & 30.6 & 23.8 & 9.8 \\
\hline & Training, CSR managers & 8.8 & 37.3 & 35.2 & 16.1 & 2.6 \\
\hline \multirow{7}{*}{$\begin{array}{l}\text { Construction } \\
\text { Stage }\end{array}$} & Architect & 18.7 & 41.5 & 23.8 & 13.0 & 3.1 \\
\hline & Client representative & 45.6 & 35.8 & 14.0 & 2.1 & 2.6 \\
\hline & Project manager & 65.8 & 23.3 & 6.7 & 2.6 & 1.6 \\
\hline & Commercial manager & 28.5 & 50.8 & 16.6 & 2.6 & 1.6 \\
\hline & Sustainability manager & 16.1 & 47.7 & 24.9 & 9.8 & 1.6 \\
\hline & Regeneration manager & 14.0 & 22.8 & 19.2 & 32.1 & 11.9 \\
\hline & Training, CSR managers & 10.4 & 35.2 & 38.3 & 15.0 & 1.0 \\
\hline \multirow{7}{*}{$\begin{array}{l}\text { Post } \\
\text { Construction } \\
\text { Stage }\end{array}$} & Architect & 15.5 & 25.4 & 28.0 & 24.4 & 6.7 \\
\hline & Client representative & 28.5 & 36.8 & 20.2 & 12.4 & 2.1 \\
\hline & Project manager & 13.5 & 26.4 & 24.4 & 27.5 & 8.3 \\
\hline & Commercial manager & 12.4 & 24.4 & 30.1 & 25.9 & 7.3 \\
\hline & Sustainability manager & 19.7 & 23.8 & 28.0 & 21.8 & 6.7 \\
\hline & Regeneration manager & 21.2 & 21.2 & 14.5 & 24.9 & 18.1 \\
\hline & $\begin{array}{l}\text { Training, } \\
\text { managers }\end{array}$ & 5.7 & 32.1 & 31.6 & 25.4 & 5.2 \\
\hline
\end{tabular}

Table 4: RII Readings; mean scores and rankings of practitioner's level of involvement in three main stages of sustainable regeneration projects

\begin{tabular}{|c|c|c|c|c|c|c|c|c|c|c|}
\hline \multirow{2}{*}{$\begin{array}{l}\text { Stakeholders (key } \\
\text { players) }\end{array}$} & \multirow{2}{*}{$\mathrm{N}$} & \multicolumn{3}{|c|}{ EARLY STAGE } & \multicolumn{3}{|c|}{$\begin{array}{l}\text { CONTRUCTION } \\
\text { STAGE }\end{array}$} & \multicolumn{3}{|c|}{$\begin{array}{l}\text { POST } \\
\text { CONTRUCTION } \\
\text { STAGE }\end{array}$} \\
\hline & & $\begin{array}{l}\text { Mean } \\
(\mathrm{M})\end{array}$ & RII & $\begin{array}{l}\text { Rank } \\
\text { /most } \\
\text { involved }\end{array}$ & $\begin{array}{l}\text { Mean } \\
\text { (M) }\end{array}$ & RII & $\begin{array}{l}\text { Rank/ } \\
\text { most } \\
\text { involved }\end{array}$ & $\begin{array}{l}\text { Mean } \\
(\mathrm{M})\end{array}$ & RII & $\begin{array}{l}\text { Rank } \\
\text { /most } \\
\text { involved }\end{array}$ \\
\hline Architect & 193 & 1.83 & 0.37 & 3 & 2.40 & 0.48 & 5 & 2.81 & 0.56 & 3 \\
\hline $\begin{array}{l}\text { Client } \\
\text { representative }\end{array}$ & 193 & 1.58 & 0.32 & 1 & 1.80 & 0.36 & 2 & 2.23 & 0.45 & 1 \\
\hline Project manager & 193 & 2.30 & 0.46 & 4 & 1.51 & 0.30 & 1 & 2.91 & 0.58 & 4 \\
\hline
\end{tabular}




\begin{tabular}{|l|l|l|l|l|l|l|l|l|l|l|}
\hline $\begin{array}{l}\text { Commercial } \\
\text { manager }\end{array}$ & 193 & 1.67 & 0.33 & 2 & 1.98 & 0.40 & 3 & 2.91 & 0.58 & 4 \\
\hline $\begin{array}{l}\text { Sustainability } \\
\text { manager }\end{array}$ & 193 & 2.41 & 0.48 & 5 & 2.33 & 0.47 & 4 & 2.72 & 0.54 & 2 \\
\hline $\begin{array}{l}\text { Regeneration } \\
\text { manager }\end{array}$ & 193 & 2.96 & 0.59 & 7 & 3.05 & 0.61 & 7 & 2.97 & 0.59 & 7 \\
\hline $\begin{array}{l}\text { Training, CSR } \\
\text { managers }\end{array}$ & 193 & 2.66 & 0.53 & 6 & 2.61 & 0.52 & 6 & 2.92 & 0.58 & 4 \\
\hline
\end{tabular}

\section{Discussion of the results}

The analysis of the questionnaire survey results, as per mean scores (M) and RII in Table 4 revealed that, clients' representatives $(M=1.58 ; R I I=0.32)$, commercial managers $(M=1.67$; $R I I=0.33)$ and architects $(M=1.83$; $R I I=0.37)$ were the three most involved practitioners during the early stages of projects' delivery. These findings were supported by "always involved" findings obtained in Table 3. In support of existing literature (Idoro, 2009; Ali, et al., 2011), it can be seen that architects, commercial managers and clients' representatives are still playing leading roles, and are predominantly involved more than other practitioners in planning and preparation activities at the early stages of the sustainable regeneration projects delivery. At the early stage of any project development, the client is expected to assemble a team to carry out his/her vision. According to Hussin, (2009), this phase involves putting in place the requisite drawings, programmes and strategies as well as selecting the appropriate resources for the project. Conventionally, at the early stage of a project's delivery, where planning and preparation activities are carried out, is considered the domain for clients or clients' representatives and architects and in some instances, commercial managers. A study carried out by Ali, et al. (2011), and Hussin (2009) also identified the early stage of the project delivery as the domain for architects and clients' representatives, in which the two practitioners were heavily involved in planning and preparation activities of the projects. Their works also lend support to the above findings.

It is suggested that the early stage of every project's development is crucial because any decision made at this stage has far-reaching implications for the project's overall outcomes. Toor and Ogunlana's (2009: 163) study of a construction project's critical success factors has revealed that "most of the highly rated critical success factors are related to the active involvement of clients or their representatives and other key practitioners at the projects" early developmental stages. Smith and Jagger (2007: 38), in their earlier work, agreed to the aforementioned argument that decisions which are taken during the early stages of the project's development; for example at the briefing and feasibility stages, results in "more far reaching economic consequences than the relatively limited decisions which can be made later in the process". This is because once the project kicks off, the opportunity to introduce and maximise the sustainability potential benefits for instance, is reduced to a minimum and in most cases, missed out.

The high level of involvement of clients or clients' representatives at the early stage as per the above findings (Table 3 and 4), could also be due to the fact that clients will always want to ensure that their projects are planned and designed to meet the time, cost and quality requirements. However, it is asserted that plans and strategies carried out at 
this stage of regeneration project development have an impact and implications not only on the cost, time and quality aspects of the projects, but also on the performance of sustainability functions of the projects (Pitt, et al., 2009). Hence, clients or their representatives need to be aware of that, particularly when they are engaging practitioners' services at this stage to deliver their sustainable regeneration projects. Similarly, clients are also very particular about the quality of their projects, hence their desire to always engage competent architects at the very early stages of their projects' development to provide them with the design solutions that will meet their needs.

For most clients and construction organisations, the early involvement of commercial managers provides the opportunity for them to seek early advice about the cost implications of adopting and implementing sustainability features on their projects. It can also be observed that early involvement of architects, clients' representatives and commercial managers tends to be in line with the traditional approaches often adopted, to involve key practitioners in the planning and the preparation activities at the early stages of construction projects. Traditionally, the first port of call when clients want to procure practitioners' services for their proposed projects is the architects and other selected practitioners who they believe will help them achieve their objectives. The above position is supported by Smith's (2006) work in which he indicated that many construction projects have been planned and procured only with selected groups of practitioners, just to meet some limited or specific projects' objectives for the clients. Hence, it can also be inferred from the above findings, that clients' representatives, architects and commercial managers' high level of involvement at this stage of the project delivery is due to the particular roles they play in making sure that planning and preparation activities of the projects achieve certain specific objectives for clients (Smith, 2006). However, the reliance on such limited practitioners' contributions and the traditional approach of involving practitioners in the planning and preparation activities at the early stage of the project's development has a number of problems, most especially when the projects are of a sustainability nature. Such an approach will largely limit the projects' success factors to cost, time and quality objectives and in the case of sustainable regeneration, relegates the sustainability aspects to the background. It is argued that the successful delivery of sustainable regeneration lies in adequate and early involvement of all the key practitioners, particularly at the early phase (OGC, 2011). Hence, the early and adequate level of involvement of all the key practitioners will inevitably enable greater planning and preparation of the projects' critical success factors beyond the current cost, time and quality objectives, to include the sustainability deliverables of the projects.

Surprisingly, a greater number of practitioners (project managers, commercial managers, sustainability managers, regeneration managers, and training/CSR managers) can be seen not to be involved during the early stages of the projects' development in undertaking planning and preparation activities. A number of factors can be seen to have accounted for this; the obvious ones include practitioners' roles, (their professional background) demands from clients and the projects' requirements have played a major part in determining practitioners' level of involvement during the early stage of the projects' delivery. However, delivering sustainable regeneration projects is about the responsibility of all the key practitioners to contribute to the planning and preparation activities of the projects. It is argued that construction projects' sustainability 
"performance outcomes depend upon inputs" from different players (Smyth, 2008: 635). Practitioners such as project managers and others with sustainability responsibilities are crucial in the sense that their early involvement will enable them to understand clients' needs as well as the projects' requirements, to translate them into practice during the construction stage of the projects.

It can also be seen from the findings that practitioners who have sustainability specifically assigned to their roles and responsibilities were least involved at the planning and preparation activities during the early stages of the projects. This could also be due to the fact that the priorities and interests of most clients and construction organisations were/are driven by considerations other than the sustainability aspects of their projects. Similarly, these categories of practitioners' level of involvement at the early stage of the projects, as per the findings, is consistent with Murray and Cotgrave's (2007) study conducted with local authorities in England and Wales, in which it was observed that practitioners (except clients representatives and architects) were 'differentiated' and were less involved in the design and planning activities at the early stages of many building projects.

Construction activities have limited duration, therefore early and adequate level of involvement of training/CSR managers for example, can enable them to identify the right caliber of people for training, to enable them to put in place the kind of training that can be offered within the projects' durations. The stage at which involvement of such key practitioners takes place has the potential to determine what and when certain sustainability features can be prepared and planned, adopted and implemented, and also monitored and evaluated on the projects. From the perspective of sustainable regeneration, the requirement to achieve sustainability of regeneration projects calls for more integrated and proactive approaches to the early and adequate level of involvement of key practitioners in the planning and preparation activities of the projects. Similarly, since sustainability features have often being a subject of contention in construction projects and difficult to deal with in practice, such early and adequate level of involvement of all the key practitioners would enable different perspectives of sustainability features to be incorporated into the planning and preparation activities of projects in a proactive manner. It is suggested that the key to any successful regeneration project is about the practical involvement of all the key practitioners, particularly at the early stage of the project's development (Takim, 2009). Likewise, such 'early and adequate' engagement would not only provide an avenue for practitioners to pursue a common sustainability course, but would also provide an enabling environment to proactively respond to any potential issues that may undermine the planning and preparation activities of the projects. Consequently, any act of inadequate involvement of all key practitioners, particularly those with sustainability responsibilities at the early stage of sustainable regeneration projects, could jeopardise the achievement of the projects' sustainability outcomes. It can however be suggested that practitioners, if well involved early in the planning and preparation activities, could be instrumental in advising many clients and construction organisations on the issues of sustainability for the adoption and implementation of such sustainability features in their projects at the construction stage. The opportunity for practitioners to develop new ideas of sustainability issues during this stage of the project could also be maximised (Tippett et al., 2007). 
At the construction stage, practitioners owe it a duty to ensure that activities are well adopted, implemented, supervised and coordinated, to meet the required standards of the projects (Hussin, 2009). At this stage, the involvement of practitioners is mainly concerned with the adoption and implementation of activities from the early stage, coordinating and supervising activities, including the workforce. From the mean and RII results (Table 4), it can be observed that, at the construction stage, three practitioners; clients' representatives $(M=1.80 ; \mathrm{RII}=0.36)$, project managers $(\mathrm{M}=1.51 ; \mathrm{RII}=0.30)$ and commercial managers $(M=1.98$; RII $=0.40)$ were the most involved in the adoption and implementation, as well as in the coordination and supervision activities for the projects. The project managers were ranked the most involved practitioners, followed by the clients' representatives, commercial managers and architects, respectively during the construction stage of the projects. Similarly, these findings were also reinforced by "always involved" obtained in Table 3.

It is obvious that this is the stage of the project delivery where a number of construction activities are adopted and implemented. This stage is also considered the domain for project managers, clients' representatives, commercial managers and architects. The coordination and supervision activities are also greater at this stage of the project development. Hence, most clients' representatives will be interested in the coordination and supervision activities as well as the adoption and implementation activities, in line with their budget, quality and time requirements. On the other hand, the project managers' coordination and supervision activities are crucial at this stage in ensuring that the physical projects are delivered to meet the projects requirements. Likewise, commercial managers are also expected to supervise and coordinate the cost management processes of the projects. The involvement of architects is also fundamental here too, in making sure that they supervise and coordinate activities to deliver the projects according to the designs of the projects. According to Hussin (2009), the involvement of architects at this phase of the project would enable them to supervise and coordinate work quality in line with their design and specifications.

It is further observed from findings (Table 4) that practitioners such as; sustainability managers $(M=2.33 ; R I I=0.47)$, regeneration managers $(M=3.05 ; R I I=0.67)$ and training/CSR managers $(M=2.61 ; R I I=0.52)$ (with assigned sustainability roles and responsibilities) were among the least involved in carrying out adoption, implementation, coordination and supervision activities on the projects. Similarly, these results were strongly backed by "always involved" results obtained in Table 3. For this group of practitioners, it can be suggested that because they are not seen as practitioners who primarily contribute to meeting the conventional projects' cost, time and quality objectives, their contributions at the construction stage could be ignored, especially, when clients and their construction organisations involved in the delivery of the projects are not inclined to sustainability issues. In this regard, most clients and construction organisations will tend to concentrate on their core business objectives, rather than pursuing and venturing into other new areas they consider will increase their expenditures (Williams et al., 2013).

At the post construction stage, which is obviously after the completion of the physical project, some of the main activities which are required to be undertaken involve performance monitoring and evaluation of the completed projects. Apparently, this is 
one of the stages of the project's delivery where the activities carried out from the early stage through to the construction stage of the projects are required to be monitored and evaluated, to provide the opportunity to ascertain the performance of the completed projects. In a study conducted by Williams et al. (2013), nearly $85 \%$ of practitioners who were involved in the study strongly agreed with the view that the use of post project monitoring and evaluation could contribute to learning and also assist in improving the project's sustainability performance of completed sustainable construction projects.

The findings (as per the mean and RII scores - Table 4) further revealed that, at the post construction stage of the project, clients' representatives $(\mathrm{M}=2.23$; $\mathrm{RII}=0.45)$ were the most involved practitioners in undertaking monitoring and evaluation activities of the project. These results further lend support to the recent study conducted by Williams et al. (2013), in which it was observed that the majority of key practitioners were not involved in post project monitoring and evaluation activities, whenever their projects were completed and handed over. Conventionally, the involvement of practitioners in many construction projects has been concentrated on the construction stage. For most 'normal' construction projects, when the major physical works are completed and the projects are handed over, only a limited number of practitioners are needed to carry out certain corrective works. Hence, their low level of involvement at this stage of the project delivery by the majority of practitioners as per the findings, typifies practitioners' level of involvement in such 'normal' construction projects. However, the situation can be seen to be different when it comes to sustainable regeneration projects. The sustainability performance requirements for regeneration projects go beyond the completion of the physical projects on site. The impact of sustainability aspects of regeneration projects, and in particular the socio-economic ones on the quality of life of society, extend far beyond the construction stage of the projects. As a result, several other issues which can impact on the sustainability performance of the projects will require attention after the practical completion of the projects. Likewise, the opportunity to monitor and undertake the evaluation of the sustainability performance of the completed projects to enable learning for future projects also becomes crucial at this stage of the projects' delivery. Consequently, in recognition of this, Williams, et al., (2013) have emphasised the need for an active and adequate level of involvement of key practitioners in the monitoring and evaluation of the sustainability aspects of their sustainability projects upon completion. It is believed that such an approach could result in the optimisation of practitioners' learning experiences and understanding of potential benefits of sustainability features for future regeneration projects.

Overall, it can be observed from the findings (Tables 3 and 4) that clients' representatives' were the most involved practitioners among other six key practitioners who participated in the study. Their high level of involvement has been consistent throughout the three delivery stages (early, construction and post construction) of the projects. Architects and commercial managers were the next most involved practitioners, with their high levels of involvement occurring at the early and construction stages of the projects' delivery. The project managers' level of involvement was also seen to be high at the construction stage, but with a low level of involvement at the early and post construction stages of the projects' delivery. The findings also indicated that, practitioners who have sustainability assigned to their roles and responsibilities such as; 
the regeneration managers, sustainability managers, training/CSR managers were the least involved in all the three stages of the projects. The Figure 1 below shows the graphical presentation of practitioners' level of involvement.

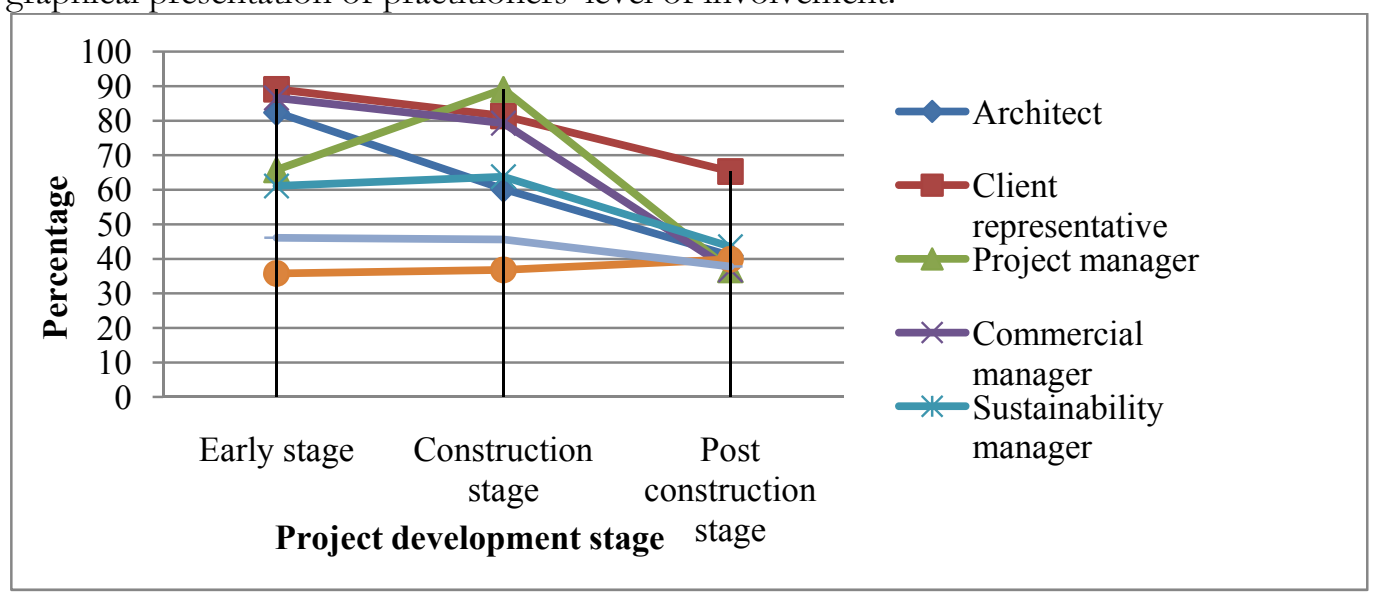

Figure 1: Graphical presentation of practitioners' level of involvement in three main project stages

One other issue that can be inferred as a reason for the varied levels of practitioners' involvement is the nature and types of current building contracts employed to procure and deliver sustainable regeneration projects. A study by Akintoye and Main (2007) on collaborative relationship in construction cited in Williams et al. (2013) claimed that the type of contract used in delivering construction projects can be a major determinant of practitioners' level of involvement and collaboration on the projects. Building contracts such as the Joint Contract Tribunal (JCT), New Engineering Contract (NEC) and other standard forms of contracts currently in use, are seemingly in tune with the traditional procurement and delivery methods for 'normal' construction projects. Their emphasis and wording are focused on the contractual relationship between the client and contractor, rather than ensuring an individual key practitioners' involvement in the delivery of the projects. Hence, the need for the construction industry practitioners to review the current building contracts to reflect the issues that are concerned with the level of involvement of key practitioners in the delivery of the projects, in particular, the sustainable regeneration ones. It is believed that such an approach will make it mandatory for clients and other clients' organisations to ensure that the key practitioners who are required to deliver sustainable regeneration projects are actively and adequately involved. The manner in which regeneration projects can generate sustainability benefits will largely depend on the roles, responsibilities and contributions from practitioners, and the stage of project's delivery at which they are brought on board. Lombardi (2009) argues that, by taking different experts and practitioners' perspectives into account, and by developing a formalised approach to engaging such key practitioners, a meaningful realisation of the projects' sustainability deliverables can be arrived at in a holistic manner. 


\section{Conclusion}

Drawing from the findings, it can be observed that the levels at which practitioners, have been involved in the delivery of sustainable regeneration projects and also at different stages of the projects' delivery vary significantly. Various factors are said to have accounted for these varied levels of involvement. These include the projects requirements and the types of regeneration projects practitioners' organisations were involved in. These factors have played a major part in determining the key practitioners who were needed to help deliver those projects' requirements, although it can be observed from the findings that all the key practitioners have had some level of involvement in delivery of the sustainable regeneration projects. Furthermore, at the early stage of project delivery where planning and preparation activities are required to undertaken, the findings from the study revealed that, clients' representatives commercial managers and architects were the three most involved practitioners in undertaking the aforementioned activities during the early stages of projects delivery. The 'high and adequate' early involvement of clients' representatives, architects and commercial managers was attributed to their particular roles and responsibilities in making sure that planning and preparation of the projects achieves certain specific objectives for the clients. A further observation also made from the findings in relation to the early stage of involvement suggested that the delivery of many regeneration projects were/are still following the traditional projects' delivery and management methods in which architects and clients' representatives are largely seen as key practitioners and tend to play leading roles during a project's early delivery stages, as evident in the findings of this study. At the construction stage, where supervised and coordinated activities were/are supposed to be adopted and implemented, it was observed from the findings that, three practitioners; clients' representatives, project managers and commercial managers were the most involved in carrying out the supervision and coordination activities as well as adoption and implementation activities for the projects. At the post construction stage, where performance monitoring and evaluation activities were/are required to be undertaken, it was observed that clients' representatives were the most involved practitioners in undertaking monitoring and evaluation activities of the project. The findings also revealed that practitioners who have sustainability assigned to their roles and responsibilities (regeneration managers, sustainability managers, training/CSR managers) were the least involved in all the three delivery stages of the projects. Their low level of involvement was also consistent throughout the three main delivery stages of the projects. Their low level of involvement was assumed to be because sustainability issues were not seen as the main priorities and considerations for the projects by most of their clients and their construction organisations. Another reason attributed to the varied levels of practitioners' involvement, was the nature and types of current building contracts employed to procure and deliver sustainable regeneration projects. The authors were of the view that the emphasis and wording of the current building contracts such as the JCT and NEC were too limited to the contractual relationships between the client(s) and the contractor(s). Therefore the study called for a review of their contents to reflect the issues that have impact/effect on the level of involvement of key practitioners in the delivery of sustainable regeneration projects, in particular, those with the assigned 
sustainability roles to oversee their core responsibilities in the delivery of the sustainability aspects of the projects.

\section{References}

Adamson, D. (2010), Community empowerment: Identifying the barriers to "purposeful" citizen participation, International Journal of Sociology and Social Policy, 30 (3/4), 114-126.

Ali, A.S; Rahmat, I; Hassan, H; (2008), Involvement of key design participants in refurbishment design process, Facilities, 26 (9/10), 389-400.

Atkintoye, A. and Main, J. (2007), 'Collaborative relationships in construction: the UK contractors' perception', Engineering, Construction and Architecture Management, 14 (6), 597-617.

Audit Commission (2007), Service Inspection Report, Regeneration, West Lindsey District Council.UK.

Brandon, P.S. and Lombardi, P. (2011), Evaluating sustainable development: in the Built Environment, 2nd ed, Wiley and Sons Ltd Publication, London, UK.

Bryman, A. (2008), Social Research Methods, 3rd ed, Oxford University Press, Oxford, UK.

Carter, K. and Fortune, C. (2007), Sustainable development policy perceptions and practice in the UK social housing sector, Construction Management and Economics,25 (4), 399-408.

Communities and Local Government (2009), Transforming Places; Changing Lives - A Framework for Regeneration: Summary of Consultation Responses. London.

Communities and Local Government (2008), Transforming Places; Changing Lives: A framework, for regeneration, London.

DBIS (2013), Industrial Strategy: government and industry in partnership, Construction Strategy 2025, Department for Business, Innovation and Skills, HM Government, London.

Dixon, T. (2006), Integrating Sustainability into Brownfield Regeneration: Rhetoric or Reality? - An Analysis of the UK Development Industry, Journal of Property Research, 23(3), 237-267.

Edum-Fotwe, F. T and Price, A.D.F (2009), A social ontology for appraising sustainability of construction projects and developments, International Journal of Project Management, 27(4), 313-322.

Feige, A; Wallbaum, H and Krank, S. (2011), Harnessing stakeholder motivation: towards a Swiss sustainable building sector, Building Research \& Information, 39 (5), 504-51.

Fellows, R and Liu, A. (2003), Research Method for Construction, Blackwell Publication Company, 2nd ed, Oxford, UK.

Haran, M; Newell, G; Adair, A; McGreal, S; Berry, J. (2011), The performance of UK regeneration property within a mixed asset portfolio, Journal of Property Research, 28 (1), 75-95.

HM Treasury (2007), Review of sub-national economic development and regeneration, Her Majesty Office, July 2007, London.

Hussin, A.A. (2009), Roles of professionals in construction industry, The International Conference on Economics and Administration, Faculty of Administration and Business, University of Bucharest, Romania ICEA - FAA Bucharest, 14-15th November 2009.

Idoro, G.I. (2009), Clients' perception of construction project leaders in the Nigerian banking industry, Journal of Engineering, Design and Technology, 7 (3), 264-28.

Jaillon, L and Poon, C.S. (2008), Sustainable construction aspects of using prefabrication in dense urban environment: a Hong Kong case study, Construction Management and Economic, 26 (9), 953-966.

Jones, P., Hillier, D., Comfort, D. (2003) Urban Regeneration Companies and City Centre: Management Research News, 26 (1), 54-63.

Lombardi, P. (2009), Evaluation of sustainable urban redevelopment scenario, Proceedings of the Institution of Civil Engineers, Urban Design and Planning, 162(4), 179-186.

Mang, P and Reed, B. (2012), Designing from place: a regenerative framework and methodology, Building Research \& Information, 40(1), 23-38.

Matar, M. M; Georgy, M.E; Ibrahim M. E. (2008), Sustainable construction management: introduction of the operational context space (OCS), Construction Management and Economics, 26(3), 261-275.

Mathur, V.N; Price, A.D.F and Austin, S. (2008), 'Conceptualizing stakeholder engagement in the context of sustainability and its assessment', Construction Management and Economics, 26(6), 601- 609.

Murray, P.E and Alison J. Cotgrave, A. J. (2007), Sustainability literacy: the future paradigm for construction education, Structural Survey, 25(1), 7-23. 
Office of Deputy Prime Minister (2005), Planning Policy Statement 1: Delivering Sustainable Development, UK.

Office of Government Commerce (OGC, 2011) Sustainability: The achieving excellence in construction procurement guide. London.

Opoku, A. and Ahmed, V. (2014), Embracing sustainability practices in UK construction organizations: Challenges facing intra-organizational leadership, Built Environment Project and Asset Management, 4(1), 90-107.

Pitt, M; Tucker, M; Riley, M; Longden, J. (2009), Towards sustainable construction: promotion and best practices, Construction Innovation, 9(2), 201-224.

Reyes, J.P; San-José, J.T; Cuadrado, J; Sancibrian, R. (2014), Health \& Safety criteria for determining the sustainable value of construction projects, Safety Science, 62(1), 221-232.

Rowlinson, S and Cheung, Y.K.F. (2008), 'Stakeholder management through empowerment: modelling project success', Construction Management and Economics, 26(6), 611 - 623.

Saunders, M., Lewis, P and Thornhill, A. (2009), Research Methods for Business Students, 5th ed., England: Prentice Hall.

Seale, C. (2005), Researching Society and Culture, 2nd Sage Publications, London.

Smith, R. (2006), Housing Stock Transfer: Investing in Renewal as a Tool for Sustainable Regeneration, Housing Studies, 21(2), 269-282.

Smith, J and Jaggar, D. (2007), 'Building Cost Planning for the Design Team', Butterworth-Heinemann, Oxford, UK.

Smyth, H. (2008), 'The credibility gap in stakeholder management: ethics and evidence of relationship management', Construction Management and Economics, 26: 6, 633 - 643.

SDC (2003), Mainstreaming sustainable regeneration: A call to action. A Report by the UK Sustainable Development Commission, London.

Takim, R. (2009), The Management of Stakeholders' Needs and Expectations in the Development of Construction Project in Malaysia, Modern Applied Science; 3(5), 167-175

RIBA (2007), Outline Plan of Work, (Amended November 2008), The Royal Institute of British Architects, London.

WCED (1987), Our common future, The World Commission on Environment and Development, Oxford University Press, Oxford.

Thomson, C.S; El-Haram, M.A; Hardcastle, C. (2009), Managing knowledge of urban sustainability assessment, Engineering Sustainability, 162(1), 35-43.

Tippett, J; Handley, J.F; Ravetz, J. (2007), Meeting the challenges of sustainable Development - A conceptual appraisal of a new methodology for participatory ecological planning, Progress in Planning, 67(1), 9-98.

Toor, S.R and Ogunlana, S.O. (2009) Construction professionals' perception of critical success factors for large-scale construction projects, Construction Innovation, 9(2), 149-167.

UN (1992) The United Nations Conference on Environment and Development (UNCED), United Nation, Rio de Janeiro.

Van Bueren, E and de Jong, J. (2007) Establishing sustainability: policy successes and failures, Building Research \& Information, 35(5), 543-556.

Williams, T; Bouchlaghem, D; Loveday, D and Law, C. (2013), Principal contractor involvement in postoccupancy evaluation in the UK construction industry, Facilities, 31(1/2), 39-55.

Winston, N. (2009), Urban Regeneration for Sustainable Development: The Role of Sustainable Housing? European Planning Studies, 17(12), 1781-1796.

Yang, J., Shen, G.Q., Ho, M., Drew, D. S. and Chan, A. P. C. (2009), Exploring critical success factors for stakeholder management in construction projects, Journal of Civil Engineering and Management, 15(4), $337-348$. 